\title{
DESAFIOS E POSSIBILIDADES NO PROCESSO dE AVALIAÇÃ̃o DA APRENDIZAGEM DE ESTUDANTES COM DEFICIÊNCIA VISUAL NA UNIVERSIDADE'
}

\begin{tabular}{c}
\hline CHALLENGES AND POSSIBILITIES IN THE PROCESS OF EVALUATING THE \\
LEARNING OF COLLEGE STUDENTS WITH VISUAL IMPAIRMENT \\
RETOS Y POSIBILIDADES EN EL PROCESO DE EVALUACIÓN DEL APRENDIZAJE \\
DE ESTUDIANTES CON DISCAPACIDAD VISUAL EN LA UNIVERSIDAD \\
\hline
\end{tabular}

\section{Tania Mara Zancanaro Pieczkowski ${ }^{1}$ Jiovana Grapilha ${ }^{2}$}

\begin{abstract}
RESUMO: A avaliação da aprendizagem é um tema desafiador e avaliar estudantes com deficiência visual é ainda mais complexo. O estudo objetivou identificar e analisar os desafios docentes na avaliação da aprendizagem de estudantes cegos ou com baixa visão na universidade e as tecnologias assistivas que favorecem as práticas avaliativas. Para desenvolver a pesquisa, realizamos entrevistas narrativas com docentes atuantes com estudantes com deficiência visual no primeiro semestre de 2016, tendo como critério o maior tempo de atuação docente na instituição pesquisada. As entrevistas foram gravadas, transcritas, organizadas em agrupamentos temáticos e analisadas com base na análise de discurso, com amparo em referenciais Foucaultianos. A maioria dos docentes declarou o desafio de estar atento e contemplar as singularidades de cada aluno e relatou que aprendeu a trabalhar com os estudantes com deficiência visual, contando especialmente com os ensinamentos que os próprios estudantes difundiram.
\end{abstract}

PALAVRAS-ChAVE: Avaliação. Estudantes com deficiência visual. Educação superior.

ABSTRACT: Assessment of learning is a challenging subject and evaluating students with visual impairment is even more complex. The objective of this study was to identify and analyze the teaching challenges in college blind or low vision students learning evaluation and the assistive technologies that favor the evaluation practices. In order to develop the research, we conducted narrative interviews with college members whose classes had visual impairment students in the first semester of 2016, having as criterion the longest teaching time in the researched institution. The interviews were recorded, transcribed, organized into thematic groupings and analyzed based on discourse analysis, supported by Foucaultian references. Most professors reported they had learned to work with visually impaired students, relying especially on the teachings the students themselves have spread and declared upon.

KEYWORDS: Evaluation. Students with visual impairment. College education.

RESUMEN: La evaluación del aprendizaje es un tema desafiante y evaluar estudiantes con discapacidad visual es aún más complejo. El estudio tuvo como objetivo identificar y analizar los retos docentes en la evaluación del aprendizaje de estudiantes ciegos o con baja visión en la universidad y las tecnologías que los asisten, favoreciéndoles en las prácticas evaluativas. Para desarrollar la investigación, realizamos entrevistas narrativas con docentes actuantes con estudiantes discapacitados visualmente en el primer semestre de 2016, teniendo como criterio el mayor tiempo de actuación docente en la institución investigada. Las entrevistas fueron grabadas, transcritas, organizadas en agrupamientos temáticos y analizadas con base en análisis del discurso, amparadas en referenciales Foucaultianos. La mayoría de los docentes ha declarado el reto de quedarse atento y

${ }^{1}$ Submetido em: 19/03/2018 - Aceito em: 06/05/2018 - Publicado em: 18/10/2018

\begin{tabular}{|c|c|c|c|c|c|c|}
\hline (C) Rev. Educ. Perspec. & Viçosa, $M G$ & $\mathrm{y}$ & $\mathrm{n}$ & & & \\
\hline
\end{tabular}


contemplar las singularidades de cada alumno y ha relatado que aprendió a trabajar con los estudiantes con discapacidad visual, contando especialmente con la enseñanza que los propios estudiantes difundieron.

PALABRAS CLAVE: Evaluación. Estudiantes con discapacidad visual. Educación superior.

\section{INTRODUÇÃO}

Os estudos empreendidos acerca da temática da avaliação abrem novas perspectivas, considerando os movimentos vivenciados nos cenários do ensino e aprendizagem e as dúvidas e vulnerabilidades que acompanham a prática avaliativa.

Embora o processo de ensino e aprendizagem seja um movimento complexo, multifatorial e que envolve professores e estudantes, historicamente, os papéis predominantemente atribuídos ao professor é o de ensinar e ao aluno o de aprender. A presença de estudantes com deficiência pode ressignificar esses papéis, pois o professor poderá necessitar aprender as especificidades do processo de aprendizagem desses estudantes, a exemplo do uso de tecnologias assistivas, para potencializar o êxito no ensino.

A inclusão de estudantes com deficiência tem conquistado crescente importância no cenário educacional brasileiro na contemporaneidade e potencializado os desafios no processo avaliativo. A matrícula desse público na educação básica aumentou, especialmente, nas últimas duas décadas, como resultado das políticas de inclusão. Podemos mencionar, dentre outras, a Política Nacional de Educação Especial na Perspectiva da Educação Inclusiva (BRASIL, 2008), atualmente em fase de revisão; a Lei n ${ }^{\circ} 13.146$, de 6 de julho de 2015, que institui a Lei Brasileira de Inclusão da Pessoa com Deficiência - Estatuto da Pessoa com Deficiência (BRASIL, 2015) e a Lei $\mathrm{n}^{\circ} 13.409$ de 28 dezembro de 2016 que altera a Lei $\mathrm{n}^{\circ}$ 12.711, de 29 de agosto de 2012 (BRASIL, 2016), para dispor sobre a reserva de vagas para pessoas com deficiência nos cursos técnico de nível médio e superior das instituições federais de ensino.

A ampliação do acesso de estudantes com deficiência na educação básica reverbera no aumento da matrícula desses estudantes também na educação superior. De acordo com o Censo da Educação Superior 2013 (BRASIL/INEP, 2013), observa-se um crescimento significativo de 590,78\% no número de estudantes com deficiência matriculados na educação superior em dez anos: em 2003 eram 5.078; em 2011 eram 23.250 e em 2013, 29.034. No entanto, estes números, comparados ao total de estudantes matriculados no ensino superior, que é 7,3 milhões, representam um percentual baixo, de apenas $0,41 \%$ do total de matrículas, especialmente se tomarmos como parâmetro o número de pessoas com deficiência no Brasil, que conforme o Censo Demográfico 2010 é de 45.606 .048 milhões.

\begin{tabular}{l|c|c|c|c|c|c|} 
(C) Rev. Educ. Perspec. & Viçosa, $M G$ & v.9 & n.2 & p.215-229 & maio/ago. 2018 & eISSN 2178-8359 \\
\hline
\end{tabular}


Constatamos, empiricamente, em diálogos com professores, gestores e estudantes, que o movimento da inclusão, embora bastante comemorado pela perspectiva dos direitos à diferença, também representa inquietações e silenciamentos. Pesquisas acerca da acessibilidade na educação superior (PIECZKOWSKI, 2012; 2014) indicam barreiras às pessoas com deficiência visual de ordem arquitetônica, comunicacional, atitudinal, entre outras. Assim como estudantes com deficiência visual manifestam dificuldades no processo de inclusão e acessibilidade à educação superior, docentes universitários também relatam lacunas na sua formação para atuar com a diferença, o que indica que os desafios devam ser enfrentados conjuntamente. Refletir acerca da avaliação da aprendizagem de estudantes com deficiência implica refletir sobre o próprio processo de inclusão na educação superior (PIECZKOWSKI, 2012; 2014).

Este estudo baseia-se em aspectos qualitativos, que buscam compreender práticas exercidas pelos docentes universitários na avaliação da aprendizagem de estudantes com deficiência visual. A pesquisa aconteceu em uma universidade comunitária de Santa Catarina, na qual estão matriculados estudantes com deficiência visual (cegos e com baixa visão).

A deficiência visual é compreendida como baixa visão ou cegueira e, de acordo com o Decreto 5.296/04, Art. $5^{\circ} \S 1^{\circ}$, são assim conceituadas:

Cegueira, na qual a acuidade visual é igual ou menor que 0,05 no melhor olho, com a melhor correção óptica; a baixa visão, que significa acuidade visual entre 0,03 e 0,05 no melhor olho, com a melhor correção óptica; os casos nos quais a somatória da medida do campo visual em ambos os olhos for igual ou menor que $60^{\circ}$; ou a ocorrência simultânea de quaisquer das condições anteriores (BRASIL, 2004).

Em relação ao processo de avaliação da aprendizagem de pessoas com deficiência, muitas perguntas já foram feitas. Mas, ao respondê-las, outras surgem, o que orienta a busca dessa compreensão a partir de outros lugares. O problema de pesquisa que orientou o estudo aqui relatado assim se constitui: Quais os desafios docentes na avaliação da aprendizagem de estudantes com deficiência visual e que tecnologias assistivas favorecem as práticas avaliativas? Do problema de pesquisa, derivaram as seguintes questões: Quais os desafios encontrados pelos docentes no processo de ensino e aprendizagem de estudantes com deficiência visual, especialmente no que se refere à avaliação da aprendizagem? Quais tecnologias assistivas às pessoas com deficiência visual estão disponíveis na universidade pesquisada? Os docentes conhecem e adotam tais tecnologias e como elas contribuem no processo de avaliação da aprendizagem de estudantes cegos ou com baixa visão?

O objetivo geral da investigação foi identificar e analisar os desafios docentes na avaliação da aprendizagem de estudantes com deficiência visual e as tecnologias assistivas que favorecem as práticas avaliativas. 


\section{CAMINHOS METODOLÓGICOS}

A pesquisa envolveu a aplicação de entrevistas narrativas gravadas e transcritas na íntegra, com professores atuantes com estudantes com deficiência visual no primeiro semestre de 2016.

A entrevista narrativa, para Andrade (2014, p. 175), “[...] é uma possibilidade de pesquisa ressignificada no campo de pesquisa pós-estruturalista em uma perspectiva etnográfica". A autora afirma, ainda, que "[...] as narrativas são constituídas a partir da conexão entre discursos que se articulam, que se sobrepõem, que se somam ou, ainda, que diferem ou contemporizam" (ANDRADE, 2014, p. 181). Partilhamos da concepção de que uma narrativa "[...] longe de ser neutra, é rigorosa e engajada, permitindo propor maneiras alternativas de ver e pensar fenômenos" (GASTALDO, 2014, p. 12).

Para a definição dos sujeitos da pesquisa, realizamos uma aproximação inicial com a Divisão de Acessibilidade, espaço que, na instituição pesquisada, mantém registros dos estudantes com deficiência matriculados e os cursos por eles frequentados. Constatamos que no primeiro semestre de 2016 a Universidade pesquisada possuía o registro de 37 estudantes com deficiência visual (quatro cegos e 33 com baixa visão) matriculados em 17 cursos de graduação. De posse dessa informação, definimos entrevistar oito professores, sendo quatro professores de estudantes cegos, e quatro professores de estudantes com baixa visão, estes vinculados a uma das quatro Áreas Administrativas da universidade. Inicialmente, sorteamos os cursos frequentados pelos estudantes com baixa visão, contemplando um curso de cada área administrativa e, posteriormente, selecionamos um professor de estudante com baixa visão vinculado a cada área administrativa, que são: Área de Ciências da Saúde; Área de Ciências Sociais e Aplicadas; Área de Ciências Humanas e Jurídicas e Área de Ciências Exatas e Ambientais.

As entrevistas aconteceram após aprovação do projeto no Comitê de Ética em Pesquisa envolvendo seres humanos e com o Termo de Consentimento Livre e Esclarecido assinado pelos participantes do estudo. O projeto foi aprovado pelo Parecer n. 1.752 .615 e Certificado de Apresentação para Apreciação Ética (CAAE) n. 58923416.4.0000. 0116.

A identificação dos professores se deu pelo relatório de docentes atuantes com os estudantes com deficiência visual no primeiro semestre de 2016, disponibilizado pela Secretaria Acadêmica. Os sujeitos da pesquisa foram eleitos seguindo como critério o maior tempo de atuação na docência na universidade pesquisada, sendo estes convidados a participar.

Salientamos que a intencionalidade era entrevistar oito docentes, atuantes com oito estudantes diferentes: os quatro cegos e quatro dentre os que apresentam baixa visão. Contudo, só

\begin{tabular}{l|c|c|c|c|c|c} 
(C) Rev. Educ. Perspec. & Viçosa, $M G$ & v.9 & n.2 & p.215-229 & maio/ago. 2018 & eISSN 2178-8359 \\
\hline
\end{tabular}


conseguimos entrevistar professores de dois estudantes com baixa visão, vinculados às áreas de Ciências da Saúde e às Ciências Sociais e Aplicadas. As razões para a não consolidação das entrevistas das demais foi que, mesmo selecionando novos cursos, além dos inicialmente sorteados, identificamos que os estudantes são usuários de óculos, sendo assim, não se caracterizam como deficientes visuais. Nosso estudo evidenciou que, predominantemente, o próprio estudante indicou a sua condição no ato da matrícula, assumindo-se como deficiente visual, muitas vezes inadequadamente.

As materialidades empíricas (narrativas) foram organizadas em agrupamentos temáticos e analisadas com base na análise de discurso, amparada em referenciais Foucaultianos. Para Foucault, ao analisarmos discursos, devemos estar atentos, pois estes podem "[...] admitir um jogo complexo e instável em que o discurso pode ser, ao mesmo tempo, instrumento e efeito de poder, e também obstáculo, escora, ponto de resistência e ponto de partida de uma estratégia oposta" (FOUCAULT, 2005, p. 96).

Os agrupamentos temáticos resultaram da recorrência e da relevância dos discursos. Amparados em Meyer e Paraíso (2014, p. 18-19),

[...] afastamo-nos daquilo que é rígido, das essências, das convicções, dos universais, da tarefa de prescrever e de todos os conceitos que não nos ajudam a construir imagens de pensamentos potentes para interrogar e descrever/analisar nosso objeto. Aproximando-nos daqueles pensamentos que nos movem, colocam em xeque nossas verdades e nos auxiliam a encontrar caminhos para responder nossas interrogações. Movimentando-nos para impedir a "paralisia" das informações que produzimos e que precisamos descrever e analisar. Movimentamonos, em síntese, para multiplicar sentidos, formas, lutas.

Com o estudo, não houve a pretensão de chegar a respostas definitivas e generalizantes. Mas, de acordo com a perspectiva pós-estruturalista de pesquisa, compreender o que é dito pelos docentes atuantes com estudantes com deficiência visual em determinado tempo e contexto, pois, “[...] as narrativas não constituem um passado em si, mas sim aquilo que os/as informantes continuamente (re)constroem desse passado como sujeitos dos discursos que lhes permitem significar suas trajetórias escolares de determinados modos" (ANDRADE, 2014, p. 178). 


\section{NARRATIVAS DOCENTES ACERCA DO PROCESSO DE AVALIAÇÃO DE ESTUDANTES COM DEFICIÊNCIA VISUAL NA UNIVERSIDADE}

Tendo como base as narrativas dos professores atuantes com estudantes cegos ou com baixa visão na universidade investigada, procuramos destacar como os docentes percebem a avaliação desse público na educação superior.

$\mathrm{O}$ quadro a seguir destaca algumas informações com o intuito de facilitar ao leitor a compreensão do contexto da pesquisa, a exemplo da condição do estudante (cego ou com baixa visão), docente entrevistado, identificação do estudante por número da ordem das entrevistas, curso e período frequentado, a área administrativa de vinculação do curso/estudante e a data da realização da entrevista. A adoção de identificações fictícias se justifica pelo cuidado em preservar as identidades dos sujeitos da pesquisa.

Quadro 1. Relação dos docentes e estudantes e caracterização dos estudantes com deficiência visual

\begin{tabular}{|c|c|c|c|c|c|}
\hline $\begin{array}{l}\text { Relação dos } \\
\text { Docentes }\end{array}$ & $\begin{array}{l}\text { Relação dos } \\
\text { estudantes }\end{array}$ & $\begin{array}{c}\text { Curso e período do } \\
\text { estudante com deficiência } \\
\text { visual }\end{array}$ & Área & $\begin{array}{c}\text { Data e } \\
\text { realização da } \\
\text { entrevista }\end{array}$ & $\begin{array}{l}\text { Característica do } \\
\text { aluno: } \\
\text { cego/baixa visão }\end{array}$ \\
\hline Docente 1 & Estudante 1 & Pedagogia $7^{\circ}$ período & $\mathrm{ACHJ}^{*}$ & 27 jun. 2016 & Cegueira \\
\hline Docente 2 & Estudante 2 & Jornalismo $7^{\circ}$ período & $\mathrm{ACSA}^{* *}$ & 05 jul. 2016 & Cegueira \\
\hline Docente 3 & Estudante 3 & Educação Física $1^{\circ}$ período & $\mathrm{ACS} * * *$ & 15 jul. 2016 & Cegueira \\
\hline Docente 4 & Estudante 4 & Letras $3^{\circ}$ período & $\mathrm{ACHJ} *$ & 10 ago. 2016 & Cegueira \\
\hline Docente 5 & Estudante 5 & $\begin{array}{l}\text { Publicidade e Propaganda } \\
5^{\circ} \text { período }\end{array}$ & $\mathrm{ACSA}^{* *}$ & 12 ago. 2016 & Baixa visão \\
\hline Docente 6 & Estudante 6 & Farmácia $7^{\circ}$ período & $\mathrm{ACS} * * *$ & 09 ago. 2016 & Baixa visão \\
\hline
\end{tabular}

Fonte: Elaborado pelas autoras.

*Área de Ciências Humanas e Jurídicas.

**Área de Ciências Sociais e Aplicadas.

***Área de Ciências da Saúde.

Desafios encontrados pelos docentes no processo de ensino, aprendizagem e avaliação de estudantes com deficiência visual

Dentre os desafios mais citados pelos professores entrevistados, foram relatados principalmente a falta de conhecimento para atuar com o público pesquisado, a ausência de material específico disponível e a falta de acessibilidade institucional em termos arquitetônicos. A ausência ou insuficiência de acervo bibliográfico em braille para estudantes cegos também foi apontada pelos professores como um limitador, uma vez que os estudantes explicitam a eles que o texto oral não contempla as vantagens da leitura tátil e reivindicam este recurso durante as aulas. A indisponibilidade institucional dessa tecnologia assistiva 
causa "desconforto" docente, à medida que limita as possibilidades de acesso aos conteúdos pelos alunos cegos.

Com relação à falta de preparação, o Docente 3 narra que:

[...] a grande maioria não teve formação. A gente sabe que a formação docente para atuar no ensino superior é através, geralmente, de mestrado e doutorado. Porém, geralmente os mestrados e doutorados não preparam a gente para isso, eles preparam a gente para fazer pesquisa. Algumas disciplinas, às vezes, dão alguns indícios de docência (DOCENTE 3).

Nesse sentido, Anastasiou (2004) afirma que a profissão docente, por trabalhar com a mudança e a construção, é marcada pela imprevisibilidade, singularidade, incerteza, novidade, dilema, conflito e instabilidade. Em razão disso, Isaia e Bolzan (2009, p. 165) evidenciam que: "Formação e desenvolvimento profissional entrelaçam-se em um intrincado processo, a partir do qual a professoralidade vai se construindo pouco a pouco. O saber-saber e o saber-fazer da profissão não são dados a priori, mas arduamente conquistados ao longo da carreira docente". Em outras palavras, podemos afirmar que o encontro, mesmo com estudantes sem deficiência, sempre representa um desafio, pois eles nunca serão iguais. Contudo, os estudantes com deficiência visual revelam a diferença de uma forma mais explícita em relação aos demais estudantes, que sabemos, também nunca são iguais. Ao referir-se aos desafios enfrentados, o Docente 2 também destaca que:

O problema é entender as dificuldades que eles têm, porque às vezes o estudante cego, ele se retrai, não fala. Eu tive uma aluna que era praticamente cega, também no curso de jornalismo, e ela não se abria, não dizia as necessidades. Agora eu já tenho um aluno que se abre, reclama, questiona e, principalmente, não se deixa abater, participa como os outros alunos (DOCENTE 2).

O Docente 1, ao evidenciar os desafios da docência com estudantes que diferem dos padrões que a sociedade insiste em estabelecer, acrescenta que:

Os desafios estão principalmente por nossa parte, enquanto docentes, de construirmos uma perspectiva e direcionamento ético, de valorização, de respeito e de sensibilidade a estas situações, independente se são um ou dois estudantes que temos em sala de aula. [...] estes sujeitos não podem ser inviabilizados, não notados, não valorizados na sala de aula. O que é um grande desafio, principalmente para os docentes, está em aprender com quem é diferente da gente, diferente naquele sentido do ensinar e aprender, do pedagógico, no cotidiano de nossas vidas. É um grande desafio e isto quem nos possibilita são estes sujeitos (DOCENTE 1).

Os princípios do confronto e da aprendizagem mútua, presentes no movimento inclusivo, são manifestados nesse discurso. Vem primeiro o espanto em lidar com sujeitos diferentes, com necessidades desconhecidas pelo professor até então. Depois, vem a constatação de que ambos, professor e estudantes, podem aprender nesse contato. Ao mencionar a ausência de material específico disponível, o Docente 5 relata que:

\begin{tabular}{l|c|c|c|c|c|c|} 
(C) Rev. Educ. Perspec. & Viçosa, $M G$ & v.9 & n.2 & p.215-229 & maio/ago. 2018 & eISSN 2178-8359 \\
\hline
\end{tabular}


Se eu trabalhasse com imagem eu precisaria descrever para ele poder entender do que estava se tratando. Isso foi minha maior tensão enquanto eu estava ministrando a aula, de não poder deixar ele sem entender do que eu estava falando. A cada semestre tem duas ou três disciplinas que trabalham com questões práticas, de movimento (DOCENTE 5).

No que se refere à falta de acessibilidade institucional em termos arquitetônicos, o Docente 4, referindo-se a uma estudante cega manifesta que:

Ela estuda no bloco T, que é mais longe. Então, ela se atrapalha na hora de entrar e sair, isso que é mais preocupante. Quando ela tem o braille funcionando, as coisas disponíveis, é normal o trabalho com ela. Ela se dá bem com a turma, pede ajuda, ela é muito receptiva, se dá bem com os colegas. Quando ela precisa de alguma coisa ela pede, fala (DOCENTE 4).

O Docente 5 menciona que cada disciplina ministrada é um aprendizado novo e é importante compreender que o ambiente de aprendizagem deve favorecer a todos, havendo assim uma troca de experiência. O entrevistado salienta a importância de que a turma se envolva, colabore, para construir relações afetivas na universidade.

\section{Contribuições das tecnologias assistivas no processo de aprendizagem e avaliação}

Como os sujeitos aprendem? Como aprendem os estudantes com deficiência visual? Eles aprendem? Como constroem conceitos de cor ou de espaço? Essas são perguntas que normalmente o professor se faz quando depara com esse público. A forma docente de ensinar passa pelas concepções de aprendizagem que possui. Condições igualitárias de aprendizagem poderão demandar tecnologias assistivas.

Tecnologias assistivas são possibilidades de promover a autonomia, de forma que o sujeito consiga realizar as tarefas o mais independentemente possível, o que contribui para a construção de uma autoimagem positiva. Entendemos que as tecnologias assistivas contribuem para proporcionar ou ampliar habilidades funcionais de pessoas com deficiência e, consequentemente, promover vida independente e inclusão. As tecnologias assistivas surgem como tópico facilitador de acessibilidade, auxiliando nos processos de inclusão social e objetivam promover a funcionalidade, relacionada à atividade e à participação. Representam um conjunto de recursos e serviços que ajudam a minimizar as dificuldades, ampliando as habilidades funcionais de pessoas com deficiência. Assim,

Tecnologia Assistiva é uma área do conhecimento, de característica interdisciplinar, que engloba produtos, recursos, metodologias, estratégias, práticas e serviços que objetivam promover a funcionalidade, relacionada à atividade e participação, de pessoas com deficiência, incapacidades ou mobilidade reduzida, visando sua autonomia, independência, qualidade de vida e inclusão social (BRASIL, 2009, p. 9). 
De acordo com Luz, Souza e Duarte (2012), as modalidades de tecnologias assistivas estão em pleno desenvolvimento e visam acessibilidade arquitetônica, ao computador, à internet, apoios educativos e comunicação. Cada categoria oferece recursos diferentes, que podem ser utilizados pela escola ou ensino superior, para facilitar a aprendizagem dos estudantes. Os autores ainda destacam que as tecnologias assistivas viabilizam que pessoas com deficiência visual tenham melhor qualidade de vida, com mais possibilidades de serem incluídas nos espaços. Por meio dessas tecnologias, pessoas com deficiências ganham autonomia e possibilidade da realização das tarefas do cotidiano, desde as tarefas mais básicas de autocuidados, até o desempenho nas atividades do meio universitário e do exercício profissional.

Até recentemente, as tecnologias assistivas eram pouco conhecidas no contexto da universidade, inclusive porque pessoas com deficiência eram raras nesse cenário, uma vez que a expansão de matrículas de estudantes com deficiência na educação superior é um fato contemporâneo. Dentre as tecnologias assistivas, o Docente 3 declara que durante as aulas adotava recursos, especialmente o computador, e evidencia as vantagens do seu uso por uma estudante cega:

Ela usou o computador com um programa para responder a prova, outras avaliações, realizar trabalhos individuais, em grupo, duplas. Neste caso ela interagia com o grupo, e participava de todas as atividades da mesma forma que os outros (DOCENTE 3).

O Docente 3 salientou que é importante se preparar antecipadamente, conhecendo estratégias que favoreçam a educação inclusiva no ambiente da sala de aula, e, além disso, sempre ter outro meio a recorrer, caso a primeira opção falhe. Considerando a especificidade de algumas tecnologias assistivas, que frequentemente não fazem parte do cotidiano do professor, o amparo institucional se torna necessário. A narrativa que segue evidencia a importância do apoio institucional e as barreiras à inclusão quando acontecem alguns procedimentos frágeis:

\footnotetext{
No dia que a menina cega foi fazer a prova a gente solicitou com antecedência o material. Veio o computador, só que ele estava com uma voz no programa extremamente mecanizada que a acadêmica não conseguia ler. $O$ pessoal da TI (referindo-se ao setor de Tecnologias da Informação) veio, mas eles falaram que não poderiam alterar naquele momento da prova. A estudante acabou fazendo no computador dela, eu acompanhado meio que no lado dela, pois no outro ela não conseguia entender o que o leitor falava. O pessoal da TI falou que demoraria em torno de 20 minutos para eles poderem configurar com voz real. Então, eu acho que a universidade deveria ter um mecanismo, um núcleo que desse suporte aos deficientes, até mesmo com materiais (DOCENTE 3).
}

O referido docente revela desconhecer a existência do núcleo de acessibilidade na instituição, o que dá indicativos da necessidade de maior divulgação desse trabalho e de estratégias de aproximação desse setor com os professores. 
Por sua vez, o Docente 6 menciona que o estudante com baixa visão com quem atua, frequentemente adapta-se à aula pensada para toda a turma. "Não foi necessário ampliar os slides, ele sentava bem na frente e conseguia ver, e depois, em casa, no computador dele, ele ampliava" (DOCENTE 6).

Os docentes entrevistados revelam surpreender-se com detalhes da aula, antes não tensionados, aspectos antes mecanizados e tornados conscientes a partir da presença dos estudantes com deficiência na turma. Os docentes mencionam novas aprendizagens, cuidados necessários, a exemplo da necessidade de utilizar pincéis com cores fortes, contrastantes, para escrever no quadro, quando estudantes com baixa visão constituem a turma; estar atento para que este estudante seja inserido nos grupos de trabalho; cuidar para que vídeos sejam dublados; sentar próximo ao estudante para realizar a audiodescrição de recursos visuais adotados em aula, entre outras estratégias pedagógicas.

Embora em algumas situações, especialmente as que envolvem estudantes com baixa visão, estes se adaptem às estruturas existentes, cabe à universidade e aos docentes propiciar materiais adaptados para criar condições igualitárias de acesso ao conhecimento. Os programas computacionais têm se revelado importantes aliados nesse processo. O Docente 2 , referindo-se a um estudante cego, narra:

Ele usa um programa, é um programa de textos, que o computador consegue ler e converte em áudio. É um programa que a universidade tem em alguns laboratórios. A universidade tem, também, uma máquina de braille que ele usava, mas em função do programa ele deixou de usar. São de grande importância estas tecnologias (DOCENTE 2).

A presença de estudantes com deficiência visual nas turmas mobiliza os docentes a planejar antecipadamente e, acreditamos, reavaliar o que é a docência universitária. Embora o termo inclusão seja difundido como algo bom, necessário e inquestionável, a presença de tais estudantes revela ao professor e à universidade a complexidade desse empreendimento. Incluir é muito mais do que matricular, inserir e/ou tolerar. Pressupõe compreender a singularidade humana. Nesse movimento de antever as adequações necessárias, o Docente 1, atuante com um estudante cego, declara buscar em setores institucionais o apoio para a prática pedagógica.

Busquei apoio do Atento (Divisão de apoio ao estudante), buscando saber quem contribuía para esta questão dos textos, a forma como chegar ao estudante. Eu sempre busquei esta relação com o Atento e esta é uma das formas de apoio (DOCENTE 1).

Nesse sentido, percebemos que a inclusão depende das ações desencadeadas pelos docentes e também pela universidade que está em processo de aprender a "lidar" com a diferença. Concordamos com Pieczkowski (2012, p. 12) ao afirmar que "[...] incluir pressupõe adaptar as estruturas existentes para atender às necessidades educacionais de todos os estudantes".

\begin{tabular}{l|l|l|l|l|l|l} 
(C) Rev. Educ. Perspec. & Viçosa, $M G$ & v.9 & n.2 & p.215-229 & maio/ago. 2018 & eISSN 2178-8359 \\
\hline
\end{tabular}


Embora a acessibilidade arquitetônica seja a mais mencionada no cotidiano, representa apenas uma das facetas da proposta de inclusão. A acessibilidade passa também pelas dimensões: atitudinal; pedagógica; digital e das comunicações. Acreditamos que seja mais fácil construir rampas de acesso, banheiros adaptados, instalar piso podotátil, do que romper com certos conceitos (ou preconceitos) que ainda estão presentes na sociedade e, muitas vezes, no ensino superior.

Ao tentarmos entender a diferença presente nos contextos da universidade, é importante identificarmos as limitações a serem superadas, para que novas posturas inclusivas sejam construídas. As pessoas com deficiência são a diferença a partir da afirmação de uma identidade, de relações de poder. Para Silva (2014, p. 100),

[...] antes de tolerar, respeitar e admitir a diferença, é preciso explicar como ela é ativamente produzida. Uma estratégia que simplesmente admita e reconheça o fato da diversidade torna-se incapaz de fornecer os instrumentos para questionar precisamente os mecanismos e as instituições que fixam as pessoas em determinadas identidades culturais e que as separam por meio da diferença cultural.

Assim, ao falarmos em inclusão, precisamos desconstruir formas generalizantes e romanceadas de conceber essa temática, para compreendê-la na sua complexidade, como um grande desafio dos nossos tempos. Numa sociedade capitalista, neoliberal, em que o lucro a qualquer custo e a lógica do mérito individual parecem imperar, pode, a deficiência, a diferença, colocar-se como uma contracultura?

Garantir o processo de avaliação, reconhecendo a especificidade de cada sujeito, não é uma tarefa fácil. De acordo com Chizzotti (2016, p. 573), a necessidade de melhorar as condições de aprendizagem e sucesso dos alunos é fortemente defendida nos circuitos educacionais, "o desafio é transformar a avaliação em uma política que desperte e motive o interesse dos alunos pela educação escolar". Ou seja, avaliar não está desvinculado do processo de ensino e aprendizagem. Para que a escola, o conhecimento, faça sentido ao estudante, precisamos, enquanto instituição ou docentes, estar em sintonia com os estudantes, por meio do currículo, de nossas ações, da linguagem.

Segundo Chizzotti, a Conferência Internacional sobre aprender no século XXI da Organização para a Cooperação e Desenvolvimento Econômico (OCDE/CERI), realizada em 2008 , indica seis princípios fundamentais para a avaliação formativa a partir de pesquisas e estudos de caso:

1- a instauração de uma cultura de classe que encoraje a interação e a utilização de instrumentos de avaliação;

2- a definição dos objetivos de aprendizagem e acompanhamento dos progressos individuais dos alunos para esses objetivos;

3- a utilização de métodos de ensino variados para responder às necessidades diversificadas dos alunos; 
4- recorrer a métodos também diversificados para avaliar os resultados dos alunos;

5- dar feedbacks das performances dos alunos e adaptar o ensino para responder às necessidades identificadas;

6- e, finalmente, a implicação ativa dos alunos no processo de aprendizagem (CHIZZOTTI, 2016, p. 572).

A avaliação formativa deve se apoiar em estratégias para potencializar as capacidades do sujeito, a aprendizagem e, oferecer condições igualitárias. As tecnologias assistivas precisam ter seu lugar assegurado nos circuitos educacionais.

\section{CONSIDERAÇÕES FINAIS}

O conjunto de finalidades da educação superior explicita que incluir estudantes com deficiência é possibilitar a eles as condições de acessibilidade para que possam ter o desempenho esperado para esse nível de ensino. Para isso, as instituições de educação superior necessitam oferecer a acessibilidade necessária. Os estudantes com baixa visão precisam ter acesso às tecnologias assistivas adequadas, a exemplo de materiais com letra ampliada, lupa e recursos ampliadores de telas. Já, os estudantes cegos necessitam de recursos distintos em relação aos estudantes com baixa visão, a exemplo de computador com leitor de tela com programas de voz, textos transcritos para o sistema braille, pois nem sempre os recursos auditivos substituem a leitura tátil.

Compreender a complexidade da inclusão é perceber que esse processo pressupõe estar presente com participação. A inclusão na educação superior tem conquistado crescente importância nos últimos anos. Para Pieczkowski (2014, p. 113) "no contexto de expansão de vagas para a educação superior, públicos que até então representavam números pouco expressivos nas estatísticas oficiais passam a ter representatividade, constituindo-se focos para pesquisas, como é o caso das pessoas com deficiência".

Constatamos que alguns docentes revelam preocupação em relação à formação profissional desses estudantes, destacando habilidades exigidas pela profissão que demandam a visão, a exemplo do manuseio de microscópios por estudantes com baixa visão na profissão de farmacêutico. Essa foi uma das inquietações evidenciadas durante as entrevistas narrativas. Avaliar estudantes com deficiência visual é perceber, explicitamente, a diferença que sempre se manifesta em uma sala de aula, embora muitas vezes os estudantes sejam percebidos de forma uniforme e generalizante.

De acordo com a perspectiva foucaultiana de análise de discurso, com o estudo não houve a intenção de julgar os docentes em relação à forma como ensinam e avaliam estudantes com deficiência visual, mas compreender essas práticas. Esperamos, também, com esta pesquisa,

\begin{tabular}{l|c|c|c|c|c|c|} 
(C) Rev. Educ. Perspec. & Viçosa, $M G$ & v.9 & n.2 & p.215-229 & maio/ago. 2018 & eISSN 2178-8359 \\
\hline
\end{tabular}


contribuir com reflexões e conhecimentos acerca das especificidades no processo de aprendizagem e desenvolvimento de estudantes com deficiência visual na educação superior.

Como afirma Chizzotti (2016, p. 563), "Alunos e professores sabem do poder terrível da avaliação: pode abrir as sendas de um horizonte virtuoso para aprender, criar, inventar ou provocar um desastre existencial na interação educacional, que se estende pela vida".

\section{REFERÊNCIAS}

ANASTASIOU, Lea das Graças. Docência no Ensino Superior e profissionalização. In: Seminário de Pesquisa em Educação da Região Sul (Anpedsul), 4., Curitiba. 2004. Anais... Curitiba, 2004. 1 CD-ROM.

ANDRADE, Sandra dos Santos. Entrevista narrativa ressignificada nas pesquisas educacionais pós-estruturalistas. In: MEYER, Dagmar Estermann; PARAIISO, Marlucy Alves (Org.). Metodologias de pesquisas pós-críticas em educação. 2.ed. Belo Horizonte: Mazza Edições, 2014. P. 175-196.

BRASIL. Presidência da República. Casa Civil. Subchefia para Assuntos Jurídicos. Decreto n. ${ }^{\circ} 5.296$, de 2 de dezembro de 2004. Regulamenta as Leis n. 10.048, de 8 de novembro de 2000, que dá prioridade de atendimento às pessoas que especifica; n. 10.098, de 19 de dezembro de 2000, que estabelece normas gerais e critérios básicos para a promoção da acessibilidade das pessoas portadoras de deficiência ou com mobilidade reduzida, e dá outras providências. Diário Oficial [da] República Federativa do Brasil, Brasília, DF, 3 dez. 2004. Disponível em: <http://www.planalto.gov.br/ccivil_03/_ato20042006/2004/decreto/d5296.htm>. Acesso em: 11 maio 2018.

BRASIL. Ministério da Educação. Secretaria de Educação Especial. Política Nacional de Educação Especial na Perspectiva da Educação Inclusiva. 2008. Disponível em: $<$ http://portal.mec.gov.br/index.php?option=com_docman\&view=download\&alias=16690politica-nacional-de-educacao-especial-na-perspectiva-da-educacao-inclusiva05122014\&Itemid=30192 > . Acesso em: 11 maio 2018.

BRASIL. Subsecretaria Nacional de Promoção dos Direitos da Pessoa com Deficiência. Comitê de Ajudas Técnicas. Tecnologia Assistiva. Brasília: CORDE, 2009.

BRASIL. INEP. Censo da educação superior de 2013. Sinopses Estatísticas da Educação Superior - Graduação, 2013. Disponível em: <http://portal.inep.gov.br/superiorcensosuperior-sinopse>. Acesso em: 11 maio 2018.

BRASIL. Presidência da República. Casa Civil. Subchefia para Assuntos Jurídicos. Lei no 13.146, de 6 de julho de 2015. Institui a Lei Brasileira de Inclusão da Pessoa com Deficiência (Estatuto da Pessoa com Deficiência). Disponível em:

\begin{tabular}{l|c|c|c|c|c|c} 
(C) Rev. Educ. Perspec. & Viçosa, $M G$ & v.9 & n.2 & p.215-229 & maio/ago. 2018 & eISSN 2178-8359 \\
\hline
\end{tabular}


<http://www.planalto.gov.br/ccivil_03/_Ato2015-2018/2015/Lei/L13146.htm>. Acesso em: 11 maio 2018.

BRASIL. Presidência da República. Casa Civil. Subchefia para Assuntos Jurídicos. Lei no 13. 409 de 28 dez. 2016. Altera a Lei $n^{0} 12.711$, de 29 de agosto de 2012, para dispor sobre a reserva de vagas para pessoas com deficiência nos cursos técnico de nível médio e superior das instituições federais de ensino. DOU de 29.12.2016. Disponível em: <http://www.planalto.gov.br/ccivil_03/_ato2015-2018/2016/lei/L13409.htm>. Acesso em: 11 maio 2018.

CHIZZOTTI, Antonio. Políticas públicas: direito de aprender e avaliação formativa. Práxis Educativa, Ponta Grossa, v. 11, n. 3, p. 561-576, set./dez. 2016.

Disponível em:

<http://www.revistas2.uepg.br/index.php/praxiseducativa/issue/view/506/showToc>. Acesso em: 30 jun. 2017.

FOUCAULT, Michel. História da sexualidade I: a vontade de saber. 16. ed. Rio de Janeiro: Graal, 2005.

GASTALDO, Denise. Pesquisador/a desconstruído/a e influente? Desafios da articulação teoria-metodologia nos estudos pós-críticos. (Prefácio). In: MEYER, Dagmar Estermann; PARAÍSO, Marlucy Alves (Org.). Metodologias de pesquisas pós-críticas em educação. 2.ed. Belo Horizonte: Mazza Edições, 2014. P. 9-13.

ISAIA, Silvia Maria de Aguiar; BOLZAN, Doris Pires Vargas. Construção da profissão docente: possibilidades e desafios para a formação. In: ISAIA, Silvia Maria de Aguiar; BOLZAN, Doris Pires Vargas; MACIEL, Adriana Moreira da Rocha (Orgs.). Pedagogia universitária: tecendo redes sobre a educação superior. Santa Maria: UFSM, 2009. P. 163176.

LUZ, Claudia Ferreira da; SOUZA, Ana Lúcia Santos; DUARTE, Ana Cristina Santos. Educação inclusiva e tecnologias assistivas: uma análise acerca da aprendizagem de deficientes visuais. In: IV Colóquio Internacional "Educação e Contemporaneidade". São Cristovão - SE, 2012.

MEYER, Dagmar Estermann; PARAÍSO, Marlucy Alves. Metodologias de pesquisas póscríticas ou sobre como fazemos nossas investigações. In: MEYER, Dagmar Estermann; PARAIÍSO, Marlucy Alves (Org.). Metodologias de pesquisas pós-críticas em educação. 2. ed. Belo Horizonte: Mazza, 2014. P. 17-24.

PIECZKOWSKI, Tania Mara Zancanaro. Inclusão no ensino superior: barreiras relatadas pelos estudantes com deficiência. In: AnpedSul, 14., Anais... Caxias do Sul, jul./ago. 2012. Disponível em: 〈https://goo.gl/r57DX1〉. Acesso em: 11 maio 2018. 
PIECZKOWSKI, Tania Mara Zancanaro. Inclusão de estudantes com deficiência na educação superior: efeitos na docência universitária. 2014. 208f. Tese (Doutorado em Educação) - Universidade Federal de Santa Maria, Santa Maria, 2014.

SILVA, Tomaz Tadeu da. A produção social da identidade e da diferença. In: SILVA, Tomaz Tadeu da; HALL, Stuart; WOODWARD, Kathryn (Org.). Identidade e diferença: a perspectiva dos estudos culturais. 15 ed. Petrópolis, RJ: Vozes, 2014. P. 73-102.

\section{NOTAS}

\footnotetext{
${ }^{i}$ Este trabalho, originalmente, foi apresentado no I Seminário: Território, Territorialidades e Desenvolvimento Regional: os Movimentos Sociais, realizado na Universidade Comunitária da Região de Chapecó UNOCHAPECÓ e será publicado nos anais, ainda em processo de elaboração. Para esta versão, o texto passou por alterações. O artigo é decorrente de Projeto de pesquisa pela modalidade Iniciação Científica, desenvolvido em 2016, aprovado no Programa de Bolsas Universitárias de Santa Catarina (UNIEDU) com recursos do Artigo 170 da Constituição Estadual.
}

\section{Sobre as autoras}

1 Tania Mara Zancanaro Pieczkowski: Mestre em Educação pela Universidade de Passo Fundo e doutora em Educação pela Universidade Federal de Santa Maria (UFSM). Pesquisadora e professora titular C, no Programa de Pós-Graduação Stricto Sensu em Educação na Unochapecó. E-mail: taniazp@unochapeco.edu.br - ORCID: http://orcid.org/0000-0002-5257-7747

2 Jiovana Grapilha: Estudante do Curso de Pedagogia. Bolsista de iniciação Científica pelo Programa de Bolsas Universitárias de Santa Catarina (UNIEDU). E-mail: Jiovana.grapilha@unochapeco.edu.br - ORCID: http://orcid.org/0000-0002-7803-904X 